\title{
Photochemical Properties of Precipitated Solid Aerosol Produced by Burning of Titanium Microparticles under Ambient Air
}

\author{
Valery Zakharenko, Sophia Khromova \\ Boreskov Institute of Catalysis, Pr. Lavrentieva, Novosibirsk, Russia. \\ Email: zakh@catalysis.ru \\ Received February 26 $6^{\text {th }}, 2010$; revised May $4^{\text {th }}, 2010$; accepted May $7^{\text {th }}, 2010$.
}

\begin{abstract}
In order to neutralize a drastic pollution of the environment (technogenic catastrophe) it is suggested to use technogenic technologies of chemical compound decontamination. One in such technologies can be the technology using metal oxide solid aerosols which are active in removal of pollutant compounds and obtainable by combustion under ambient air of appropriate metal particles, for example, aluminum, magnesium, titanium and etc. It is shown that the titanium dioxide out of an solid aerosol, obtained by pyrotechnic mixture combustion containing titanium microparticles has optic, chemical and photocatalytic properties close to properties of titanium dioxide produced by a different way. The production of such aerosol in direct place of a technogenic catastrophe can be made for the cleaning of atmosphere near a pollution source.
\end{abstract}

Keywords: Pyrotechnic Mixture, Precipitated Aerosol, $\mathrm{Tio}_{2}$, Photoadsorption, Photocatalysis, Troposphere

\section{Introduction}

The Earth's atmosphere is ability for self-cleaning from dangerous compounds because of the photocatalytic and photosorption processes on the particle aerosol surface in the troposphere. These processes are anticipated to primary affect the intensity of acid rains, concentration of greenhouse and ozone-depleting gases, as well as cleaning up harmful compounds from the atmosphere.

However, in case of man-caused catastrophe, which accompany a local emission of pollutants, the decontamination of the atmosphere by natural aerosols may be ineffective. For the neutralization of drastic pollution of the environment can be used technogenic technologies of a chemical compound decontamination. One in such technologies can be the technology using metal oxide solid aerosols which are active in removal of pollutant compounds and obtainable by combustion under ambient air of appropriate metal particles, for example, aluminum [1], magnesium [2] and etc. It is known that magnesium oxide photosorbs efficiently halogen-containing organic compounds [3] and titanium dioxide photocatalyzes an oxidation breakdown a large number of organic compounds polluting atmosphere [4,5].

The pyrotechnic technology of a metal oxide preparation is mobile, available and inexpensive way of a solid aerosol production near a pollution source. The technical implement may be look like on a firework, lighting flare and the like. It allows locating a contaminating impact of chemical compounds. For a development of such technology the study of photochemical properties of the titanium dioxide producing by pyrotechnic mixture combustion under ambient air was carried out.

\section{Experimental}

Powdery titanium dioxide was prepared by combustion pyrotechnic mixture consisting of ammonium perchlorate, hydroxy-terminated polybutadiene (HTPB) and titanium particles (particle size from 60 to $90 \mathrm{~m}$ ) under ambient air. The highly dispersed titanium dioxide powder had the specific surface area of $6 \mathrm{~m}^{2} \mathrm{~g}^{-1}$. After a treatment of the oxide surface at temperature $625 \mathrm{~K}$ for $30 \mathrm{~min}$ in air the specific surface area was decreased to $4 \mathrm{~m}^{2} \mathrm{~g}^{-1}$. The crystal structures of rutile and anatase were confirmed by X-ray diffraction of the prepared titanium oxide powders.

A suspension of $\mathrm{TiO}_{2}$ in the distilled water was supported on the internal wall of a quartz glass reactor, which was transparent for the light with wavelength longer than $185 \mathrm{~nm}$. The $\mathrm{TiO}_{2}$ layer was dried at room temperature in air for a week. Then, without any additional treatment, the reactor was sealed to the high vacuum system for the 
photoadsorption experiments. The reactor was evacuated to 10-5 $\mathrm{Pa}$ at room temperature for several hours.

Freon 134a (asymmetric tetrafluoroethane, $\mathrm{CH}_{2} \mathrm{FCF}_{3}$ ) was provided by the State Scientific Center of Applied Chemistry (St. Petersburg). Freon $22\left(\mathrm{CHF}_{2} \mathrm{Cl}\right)$ was produced by the Ural factory "Halogen". Before experiments this compounds were cleaned additionally by freezing. The chemical composition of the freons during the course of the experiment was monitored with a mass spectrometer via their sampling through a leak valve.

The pressure into the reactor volume was measured with the Pirani gage, which was calibrated with oxygen. A necessary correction was introduced for the sensitively with respect to Freons. The composition of the gas phase was measured with a mass spectrometer made from an monopole analyzer APDM-1. The kinetics of the observed processes were registered by measuring the alteration in amplitude of the most intensive peak in the mass spectra of the corresponding substances.

A DRSh-250 high pressure mercury lamp illuminated the reactor through heat water and interference filters. An RTN-20S thermopile was used to measure the radiation intensity. In some experiments, the unfiltered radiation of the mercury lamp at > $300 \mathrm{~nm}$ was used; for this purpose the interference filter was replaced by colored glass UV filter. The total density of the radiation flux was $1 \mathrm{~mW}$ $\mathrm{cm}^{-2}$ through this filter.

The effective quantum yield was calculated as the ratio of the number of photoadsorption or photodesorption molecules to the number of quanta penetrated through the external wall of the reactor.

The diffuse reflectance spectra were taken in air on a SPECORD M40 spectrophotometer. In the studies a powder-like magnesium oxide was used as the reference standard.

\section{Results and Discussion}

\subsection{Optical Properties of Powdered Titania Samples}

We studied the absorption properties of dispersed titania after storage in air for a long period of time and after activation by heating at $625 \mathrm{~K}$ in air for $30 \mathrm{~min}$ with respect to the light from different parts of the solar spectrum. The experiments with the samples contacted with the air for a long time are especially important for evaluating theprospects of titania prepared by this method for application in processes leading to purification of the environ ment during various man-caused catastrophes.

There are three stable crystalline modifications of titania encountered in the nature in the form of rutile, anatase and brookite crystals. Titania samples of all these crys talline modifications with stoichiometric chemical composition are white powers. The absorption of light with energies below the band gap of titania in rutile modifica- tion $(\mathrm{Eg}=3.05 \mathrm{eV})$ is minimal by all such powders (Figure 1, inserts a) and b)). This absorption corresponds to the impurity absorption bands for single crystals or surface absorption for finely dispersed powders.

According to these data, there is a bend on the absorption edge curve for powdered titania samples consisting from a mixture of anatase and rutile modifications (Figure 1, inserts a) and b), curves A, B, and C). Such a bend is not observed for pure anatase (Figure 1, inserts c), curve D) or rutile (Figure 1, insert c), curve E) samples. Titania produced by Degussa contains rutile, anatase and some amorphous phase [6]. The absorption band edge of anatase powder is shifted by $0.1-0.2 \mathrm{eV}$ to shorter wavelengths compared to that of rutile powder (3.0 and 2.8-2.9 $\mathrm{eV}$, respectively).

If the titania stoichiometry is changed due to partial reduction of $\mathrm{Ti}^{4+}$ to $\mathrm{Ti}^{3+}$ and formation of lattice oxygen vacancies during the oxide synthesis, the powders become colored and absorption in the surface band of the oxide appears. Figure 1 (insert c), curve E) shows the diffuse reflectance spectrum of $\mathrm{TiO}_{2}$ sample prepared at Boreskov Institute of Catalysis, which had substantially nonstoichiometric composition and green color. According to the results of the XRD studies, such sample contained titania in rutile modification. The greenish titania sample studied by us consisted of $\mathrm{TiO}_{2}$ in rutile modification mixed with anatase. It was shown by EPR that this sample (which was used in the photoadsorption experiments) was not stoichiometric and contained $\mathrm{Ti}^{3+}$ ions. The measurements of diffuse reflectance optical density (Figure 1, insert c), curve F) also proved that of sample was not stoichiometric. The titania sample was not subjected to any treatment during registration of the spectra. A similar sample was used for deposition on the reactor walls. The diffuse reflectance optical density spectrum of titania heated in air at $620 \mathrm{~K}$ for $30 \mathrm{~min}$ is shown in Figure 1 (insert d), curve $\mathrm{H}$ ). Its spectrum is compared with that of the titania sampled from the gas mixture after combustion of the pyrotechnic mixture using a vacuum impactor (Figure 1, insert d), curve G).

Thus, the absorption of titania powders prepared by combustion of pyrotechnic mixture containing titanium microparticles in the region before the $\mathrm{TiO}_{2}$ intrinsic absorption edge (corresponding to the region of the solar troposphere irradiation spectrum) depends on the synthesis method and after-treatment of the samples.

\subsection{Chemical Properties of Titania Prepared by Combustion of Titanium Microparticles in Air}

When the reactor with deposited $\mathrm{TiO}_{2}$ was evacuated at room temperature, water and carbon dioxide were the main products released from the surface of the titania 


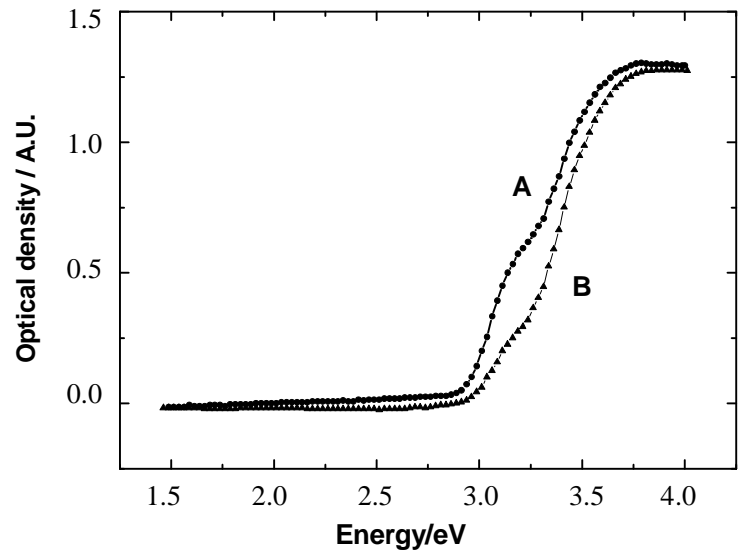

(a)

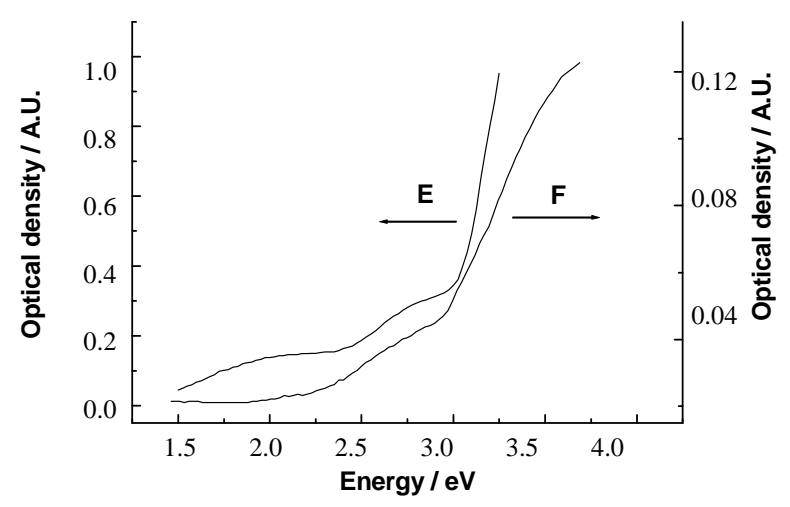

(c)

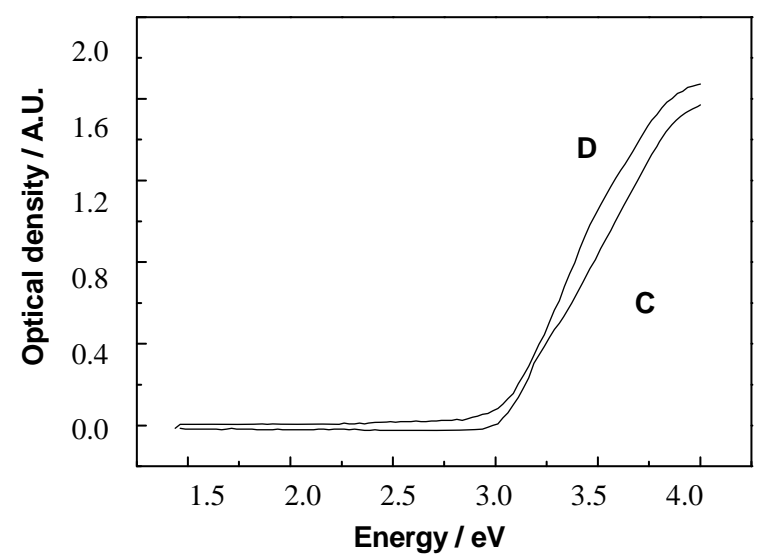

(b)

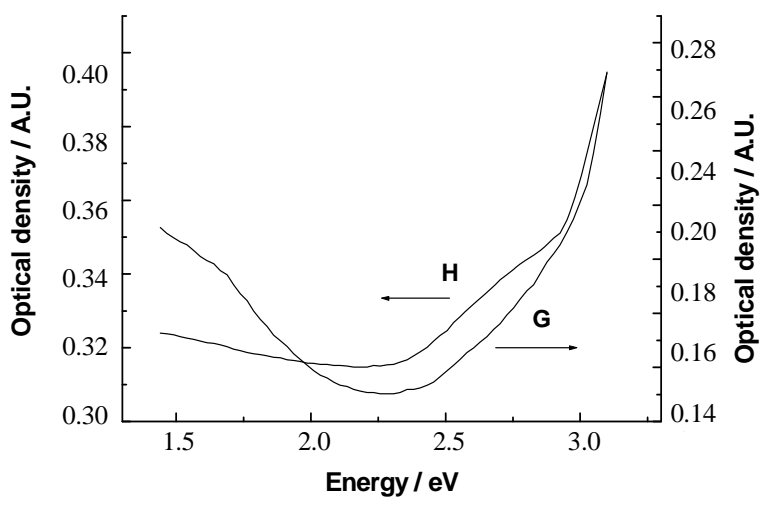

(d)

Figure 1. The diffuse reflection spectra for $\mathrm{TiO}_{2}$ samples of different mode of production; (a) A-plasmotrone production, specific surface area $3 \mathrm{~m}^{2} \mathrm{~g}^{-1}$ (Russia); $\mathrm{B}-\mathrm{TiO}_{2}$ of anatase crystal structure after an air treatment at $1270 \mathrm{~K}, 8 \mathrm{~m}^{2} \mathrm{~g}^{-1}$ (Russia, "Reachim"); (b) C-plasmotrone, $50 \mathrm{~m}^{2} \mathrm{~g}^{-1}$ (Germany, "Degussa"); D-plasmotrone, $100 \mathrm{~m}^{2} \mathrm{~g}^{-1}$ (France); (c): E-greenish TiO of rutile crystal structure, (Russia, Institute of Catalysis); $\mathrm{F}_{-} \mathrm{TiO}_{2}$ used in the present work (mixture of rutile and anatase crystal

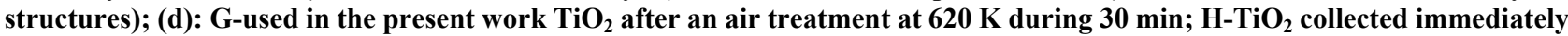
after pyrotechnic mixture combustion

powder. During the experiments described below water vapor was always present in the reactor. When the reactor volume was connected to the measurement volume, water vapor was trapped in the reactor volume in a trap with a cooling liquid (ethyl alcohol cooled to $173 \mathrm{~K}$ ). Prolonged evacuation of the reactor volume for $1 \mathrm{~h}$ in high-vacuum installation through a trap with the cooling liquid resulted in partial removal of carbon dioxide adsorbed on the titania surface. As a result, quasi-equilibrium filling of the surface with $\mathrm{CO}_{2}$ was established. The kinetics of approaching to the equilibrium $\mathrm{CO}_{2}$ pressure is shown in Figure 2, curve A. This kinetics is presented as the decrease of the amount of $\mathrm{CO}_{2}$ molecules adsorbed on the titania surface (desorption). The kinetic curve follows the first-order equation with the time constant $\tau_{1} \approx 6 \mathrm{~min}$.

No other gases except for $\mathrm{CO}_{2}$ and $\mathrm{H}_{2} \mathrm{O}$ were observed to be released in measurable amounts in the dark at room temperature from the surface of titania prepared by com- bustion of the pyrotechnic mixture containing ammonium perchlorate and organic stabilizer under ambient air.

Much more processes take place on the titania surface under visible light illumination than in the dark. In edition to the dark desorption of $\mathrm{CO}_{2}$, its photodesorption was observed with the first-order kinetics similar to that of the dark desorption ( $\tau_{2} \approx 5 \mathrm{~min}$ ) by 20 times larger amount of desorbed $\mathrm{CO}_{2}$ (Figure 2, curve B). The photodesorption kinetics is presented as the decrease in the amount of $\mathrm{CO}_{2}$ molecules adsorbed on the titania surface. Figure 3 presents the data of the mass-spectrometric analysis of changes in the intensity of the peak with mass 44 (the main peak in the mass spectrum of carbon dioxide) during illumination with light passing through the interference filters $436 \mathrm{~nm}$ and $308 \mathrm{~nm}$. The kinetics of $\mathrm{CO}_{2}$ photodesorption during illumination through the interference filter $436 \mathrm{~nm}$ (region of impurity surface absorption on $\mathrm{TiO}_{2}$, Figure 1) is different from that observed during 


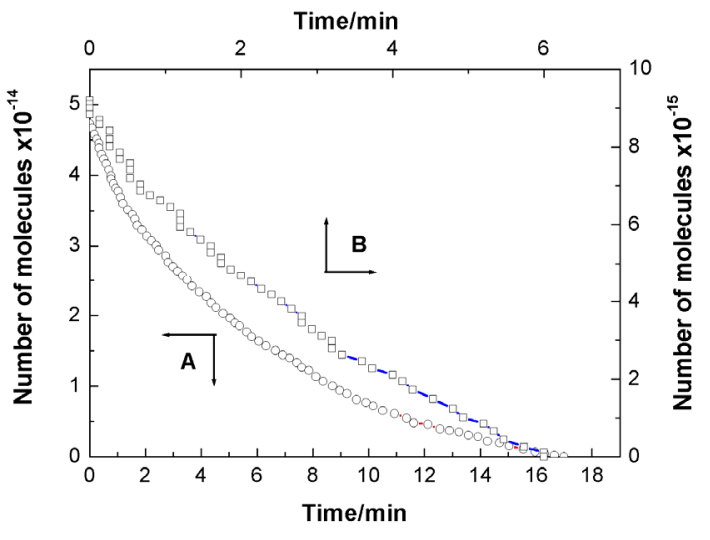

Figure 2. The kinetics of the desorption $\mathrm{CO}_{2}$ from $\mathrm{TiO}_{2}$ surface. A-decrease of number of $\mathrm{CO}_{2}$ molecules on $\mathrm{TiO}_{2}$ surface (dark desorption); B-decrease of number of $\mathrm{CO}_{2}$ (in addition to dark desorption) under illumination of $\mathrm{TiO}_{2}$ surface through the UV filter (photodesorption)

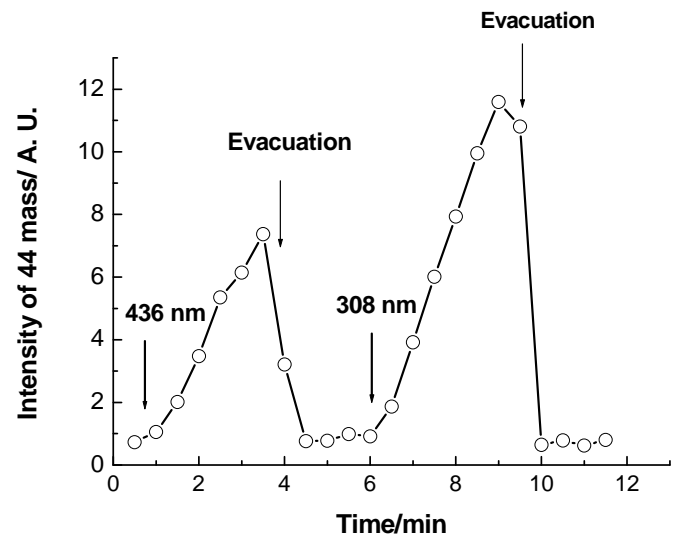

Figure 3. The kinetics of the desorption $\mathrm{CO}_{2}$ from $\mathrm{TiO}_{2}$ surface under light with wavelengths $436 \mathrm{~nm}$ and $308 \mathrm{~nm}$ (mass-spectrometry data)

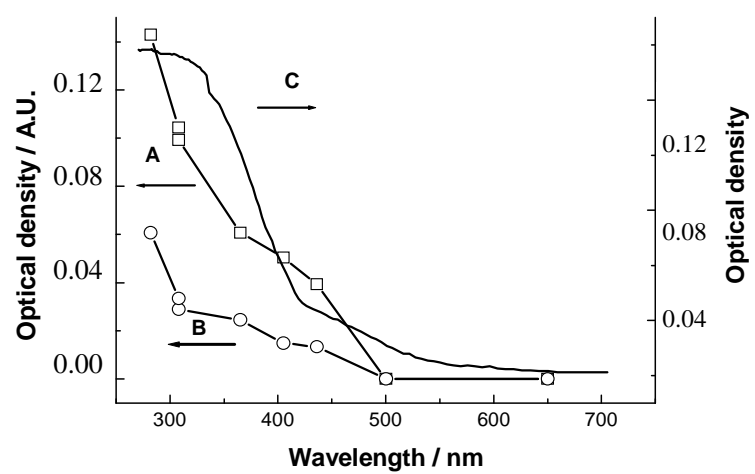

Figure 4. Spectral dependencies for titanium dioxide, prepared by burning of titanium particles under ambient air. A-photodesorption $\mathrm{CO}_{2}$ after first illumination; B-photodesorption $\mathrm{CO}_{2}$ after the long-time illumination through the UV filter; C-diffuse reflection spectrum for $\mathrm{TiO}_{2}$ which is the same as located on the wall of a reactor illumination through the interference filter $308 \mathrm{~nm}$ (region of intrinsic $\mathrm{TiO}_{2}$ absorption, Figure 1) by faster decrease of the $\mathrm{CO}_{2}$ desorption rate. In the former case, the kinetics corresponds better to the first-order reaction kinetics. Meanwhile, in the latter case during illumination with ultraviolet light (Figure 2, curve B) the kinetics is described by a linear equation.

The measurement of the spectral dependencies of the $\mathrm{CO}_{2}$ photodesorption quantum yield showed that the highest quantum yield was observed in the region of the $\mathrm{TiO}_{2}$ intrinsic absorption (Figure 4, curves A and B). A diffuse reflectance spectrum of the titania powder used in this study is shown for comparison (Figure 4, curve C). If the time of the $\mathrm{TiO}_{2}$ surface illumination was increased to several hours, the $\mathrm{CO}_{2}$ photodesorption quantum yield decreased.

The $\mathrm{CO}_{2}$ photodesorption in the region of the $\mathrm{TiO}_{2}$ intrinsic absorption (including the $308 \mathrm{~nm}$ filter) is apparently caused by deep oxidation of adsorbed hydrocarbons with the oxygen from the air [7]. The processes predominating in the region of the surface absorption are related to the electron transfer from the oxide valence band to the surface and discharging of the surface compounds (e.g. $\mathrm{CO}_{3}{ }^{-}, \mathrm{CO}_{2}^{-}$) with the electron transfer to the conduction band. In the former case, the $\mathrm{CO}_{2}$ photodesorption results from discharging of the surface carbonate and carboxylate groups [8] with a mobile hole of the valence band. In the latter case, the $\mathrm{CO}_{2}$ photodesorption to the gas phase is related to direct discharging of these compounds. The efficiency of the absorption with the formation of electron-hole pairs is substantially higher than that in the surface absorption band (see the titania diffuse reflectance spectrum, Figure 1, insert c), curve F). The quantum yield of photodesorption in the region of the oxide intrinsic absorption is also much higher than in the surface absorption band (Figure 4).

No photoadsorption of Freon $22\left(\mathrm{CHF}_{2} \mathrm{Cl}\right)$ and Freon 134a $\left(\mathrm{CF}_{3} \mathrm{CH}_{2} \mathrm{~F}\right)$ was observed under illumination with unfiltered light of the DRSh-250 mercury lamp or illumination through a UV filter over titania prepared under ambient conditions and stored in air for a long time. No photoadsorption of these halocarbons was observed in the presence of dry air as well. According to the literature data no photocatalytic oxidation of methane is observed on $\mathrm{TiO}_{2}[9,10]$. However, photoadsorption of methane and hydrogen was observed on rutile after high-temperature oxygen-vacuum treatment [11-13]. Photoadsorption of halogenated methane and ethane derivatives (Freon 22 and Freon 134a, respectively) was quite efficient on $\mathrm{MgO}$ and $\mathrm{CaCO}_{3}$ exposed in air for long time [3,14]. Photocatalytic oxidation of carbon monoxide [7] and some other gas-phase reaction, e.g. photocatalytic oxidation of $\mathrm{C}_{2+}$ alkanes [9,10,15], aromatic hydrocarbons [16], photocatalytic destruction of chlorinated ethane derivatives $[17,18]$, etc., occur efficiently on the $\mathrm{TiO}_{2}$ surface. 
In our experiments we observed oxygen photoadsorption on the $\mathrm{TiO}_{2}$ surface from the air dried by passing through a trap cooled with liquid nitrogen. Photodesorption of carbon dioxide takes place simultaneously with the oxygen photoadsorption. The initial rate of oxygen photoadsorption exceeds that of the $\mathrm{CO}_{2}$ photodesorption. So, the total pressure registered by a Pirani manometer decreases (photoadsorption). The kinetics of the oxygen concentration decrease (oxygen photoadsorption) determined from changes in the intensity of peak with mass 32 (mass-spectrometer data) is shown in Figure 5, curve A. This kinetics is described by a first-order equation with time constant $\tau_{3} \approx 3 \mathrm{~min}$. This process ends only when all oxygen from the reaction volume is photoadsorbed. Even during the first illumination the amount of photoadsorbed oxygen exceeds that of photodesorbed $\mathrm{CO}_{2}$ by a factor of 5 . The kinetic of $\mathrm{CO}_{2}$ photodesorption when oxygen is present in the gas phase is characterized by much longer time constant $\left(\tau_{4}>10 \mathrm{~min}\right.$, Figure 5, curve B) than those of the dark desorption $\left(\tau_{1}\right)$ and photodesorption of $\mathrm{CO}_{2}\left(\tau_{2}\right)$.

According to the spectral dependencies of the quantum yield of oxygen photoadsorption from dried air, the photoadsorption was more efficient in the region of the intrinsic $\mathrm{TiO}_{2}$ absorption (Figure 6, curves $\mathrm{B}$ and $\mathrm{C}$ ). The edge of the quantum yield spectrum of oxygen photoadsorption was shifted to longer wavelengths $(550 \mathrm{~nm})$ compared to that of the $\mathrm{CO}_{2}$ photodesorption $(500 \mathrm{~nm}$, Figure 4).

So, it appears that the oxygen photoadsorption on the titania sample prepared by combustion of titanium particles in air does not result from the oxygen interaction with the surface electron sites induced by illumination. The oxygen photoadsorption (consumption of oxygen from the gas phase) occurs as a reaction of oxygen molecules with compounds adsorbed from the air earlier, i.e. after syn-

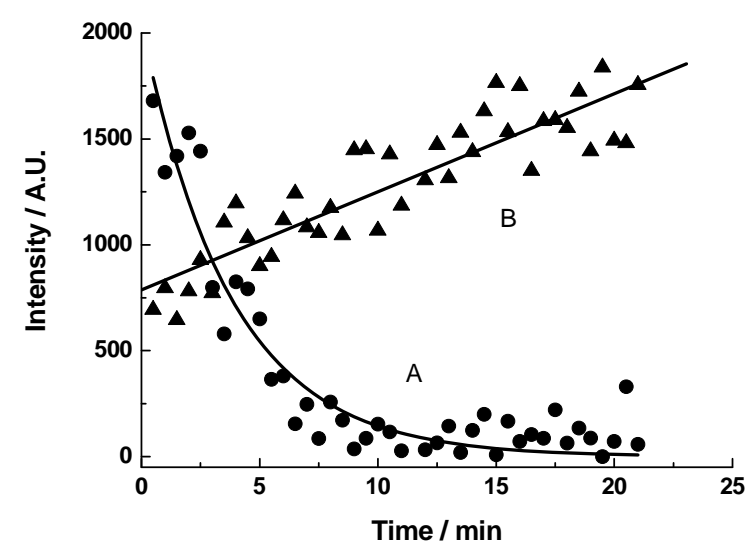

Figure 5. The kinetics of the photoinduced processes on $\mathrm{TiO}_{2}$. A-photoadsorption of oxygen from the mixture of dried air and Freon 134a (the alteration in amplitude of peak for $\mathrm{m} / \mathrm{z} 32$ in the mass spectra); $\mathrm{B}$-increase of number of $\mathrm{CO}_{2}$ molecules under illumination of $\mathrm{TiO}_{2}$ surface through the $\mathrm{UV}$ filter (photodesorption, mass-spectrometric data)

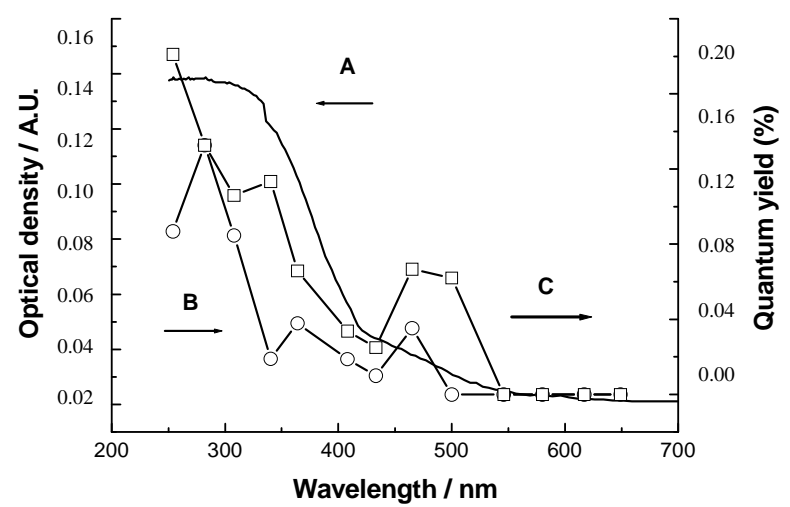

Figure 6. Spectral dependencies for titanium dioxide, prepared by burning of titanium particles under ambient air. A-diffuse reflection spectrum for $\mathrm{TiO}_{2}$ which is the same as located on the wall of a reactor; B-photoadsorption of oxygen from the dried air; C-photoadsorption of oxygen from the mixture of dried air and Freon 134a

thesis and storage of the titania sample. The registered oxygen photoadsorption kinetics is close to the first order kinetics. Meanwhile, the photoadsorption kinetics of simple gases on metal oxides (photoadsorption on surface sites generated by illumination) after the thermal vacuum treatment of the oxides is more complex $[9,11,19]$. The reaction of oxygen with adsorbed compounds is also proven by the change of the time constant of $\mathrm{CO}_{2}$ photodesorption in the presence of oxygen in the reaction volume and by the increase of the amount of $\mathrm{CO}_{2}$ formed in this case. The consumption of oxygen from the gas phase under illumination for oxidation of organic substances adsorbed on $\mathrm{TiO}_{2}$ was earlier suggested by Solonitsyn [20].

\section{Conclusions}

Thus, the optical and chemical properties of titanium dioxide prepared by combustion of a pyrotechnic mixture are close to those of titania prepared by other methods. The band gaps of $\mathrm{TiO}_{2}$ samples prepared by different methods are the same. Absorption in the spectral region below the intrinsic absorption edge, which is related to changes in the titania stoichiometry, is also observed. Photodesorption of $\mathrm{CO}_{2}$ and photoadsorption of oxygen are observed on $\mathrm{TiO}_{2}$ in wide range of the solar troposphere irradiation spectrum. No reaction of the titania surface with methane and its halogenated derivatives as well as ethane and its halogenated derivatives was observed. Meanwhile, we observed photocatalytic oxidation of carbon monoxide.

It is natural to expect that titania prepared by combustion of the pyrotechnical mixture in air will be active in the same reactions where photocatalytic oxidation is observed. These are oxidation of ethylene and its halogenated derivatives, oxidation of organic acids, alcohols, etc. If such processes take place under conditions close to those ob- 
served in the combustion zone, they can contribute to cleaning of the environment from various gaseous pollutants.

\section{REFERENCES}

[1] B. Z. Eapen, V. K. Hoffmann, M. Schoenitz and E. L. Dreizin, "Combustion of Aerosolized Spherical Aluminum Powders and Flakes in Air," Combustion Science and Technology, Vol. 176, No. 7, 2004, pp. 1055-1069.

[2] I. E. Molodetsky, E. L. Dreizin, E. P. Vicenzi and C. K. Law, "Phases Titanium Combustion in Air," Combustion and Flame, Vol. 112, No. 4, 1998, pp. 522-532.

[3] V. N. Parmon and V. S. Zakharenko, "Photocatalysis and Photosorption in the Earth's Atmosphere," CatTech, Vol. 5, 2001, pp. 96-115.

[4] M. R. Hoffman, S. T. Martin, W. Choi and D. W. Bahneman, "Environmental Application of Semiconductor Photocatalysis,” Chemical Review, Vol. 95, No. 2, 1995, pp. 69-96.

[5] X. Chen and S. S. Mao, "Titanium Dioxide Nanomaterials: Synthesis, Properties, Modifications, and Applications," Chemical Review, Vol. 107, No. 1, 2007, pp. 2691-2959.

[6] R. I. Bickley, T. G. Carreno, J. S. Lees, L. Palmisano and R. J. D. Tilley, "Structural Studies of P-25 Titanium Oxide,” Journal of Solid State Chemistry, Vol. 92, No. 17, 1991, pp. 178-186.

[7] V. S. Zakharenko, "Photoadsorption and Photocatalytic Oxidation on the Metal Oxides-Components of Tropospheric Solid Aerosols under the Earth's Atmospheric Conditions," Catalysis Today, Vol. 39, No. 3, 1997, pp. 243-349.

[8] P. Jackson and G. D. Parfitt, "Infrared Study of the Surface Properties of Rutile,” Journal of Chemical Society, Faraday Transaction I, Vol. 68, No. 1, 1972, pp. 896-906.

[9] M. Formenti, F. Juillet, P. Meriaudeau, S. J. Teichner and P. Vergnon, "Preperation in a Hydrogen-Oxygen Flame of Ultrafine Metal Oxide Particles. Oxidative Properties toward Hydrocarbons in the Presence of Ultraviolet Radiation,” Journal of Colloid and Interface Science, Vol. 39, No. 1, 1972, pp. 79-89.
[10] A. Mills and S. J. Le Hunte, “An Overview of Semiconductor Photocatalysis," Journal of Photochemistry and Photobiology A, Vol. 108, No. 1, 1997, pp. 1-35.

[11] R. J. Bickley and F. S. Stone, "Photoadsorption and Photocatalysis at Rutile Surfaces," Journal of Catalysis, Vol. 31, No. 31, 1973, pp. 389-397.

[12] S. L. Kaliaguine, B. N. Shelimov and V. B. Kazansky, "Reactions of Methane and Ethane with Hole Centers O'," Journal of Catalysis, Vol. 55, No. 3, 1978, pp. 384-399.

[13] A. Fujishima, N. R. Tata and D. A. Tryk, "Titanium Dioxide Photocatalysis," Journal of Photochemistry and Photobiology C, Vol. 1, No. 1, 2000, pp. 1-21.

[14] V. S. Zakharenko and V. N. Parmon, "Photoadsorption and Photocatalysis Processes Influencing on Earth's Atmosphere Composition," Kinetics and Catalysis, Vol. 41, No. 6, 2000, pp. 756-759.

[15] N. Djeghri, M. Formenti, F. Juillet and S. J. Teichner, "Photointeraction on the Surface of Titanium Dioxide between Oxygen and Alkanes," Faraday Discussion, Chemical Society, Vol. 58, No. 1, 1974, pp. 185-193.

[16] V. A. Isidorov, E. M. Klokova, V.G. Povarov and S. Klokova, "Photocatalysis on Atmospheric Aerosols: Experimental Studies and Modeling," Catalysis Today, Vol. 39, No. 3, 1997, pp. 233-242.

[17] M. R. Nimies, W. A. Jacoby, D. M. Blake and T. A. Milne, "Gas-Phase Photodestruction over $\mathrm{TiO}_{2}$ Powders of Various Chlorinated Ethylene," Environmental Science and Technology, Vol. 27, No. 3, 1993, pp. 732-739.

[18] M. D. Driessen, A. L. Goodman, T. M. Miller, G. A. Zaharias and V. U. Grassian, "Gas-Phase Photooxidation of Trichloroethylene on $\mathrm{TiO}_{2}$," Journal of Physical Chemistry B, Vol. 102, No. 3, 1998, pp. 549-556.

[19] A. Lisebigler, G. Lu and J. T. Yates, "Photocatalysis on the $\mathrm{TiO}_{2}$ Surfaces: Principles, Mechanisms and Selected Results," Chemical Review, Vol. 95, No. 3, 1995, pp. 735758.

[20] A. N. Terenin and Y. P. Solonitsin, "Illumination Influence over Gas Adsorption by Solids,” Discussion Faraday Society, Vol. 28, No. 28, 1959, pp. 28-31. 